\title{
家长应如何正确认识、防治孩子手机成瘾 家庭教育典型案例分析
}

邓仁平

湖南省永州市新田县龙泉第四完全小学

DOI:10.32629/jief.v2i7.1941

[摘 要] 现在的家庭教育中存在着许多误区, 其中孩子手机成瘾尤为突出, 很多家长对孩子手机成瘾一事, 既不能正确认识它的成因, 也无 法采取有效的防治措施，因此如何让孩子摆脱手机成瘾是目前急需解决的问题。

[关键词] 家庭教育; 手机; 成瘾

中图分类号: G623 文献标识码: A

30 年前, 人们认为流行音乐会毁掉下一代; 20 年前, 人们认为电视 节目会毁掉下一代; 现在人们认为手机为主的电子产品会毁掉下一代。 其实这都是一把 “双刃剑”, 但凡是成瘾不能自拔后, 的确会毁掉孩子。 孩子手机上㒣让家长非常头疼、甚至绝望无助, 作为家长应该正确认识 手机成瘾原因，防止孩子手机成瘾，笔者认为必须知其危害，不可小视； 析其成因, 自我反思; 科学施策, 防治结合。

\section{1 手机成瘧的危害}

首先损害身心健康。玩手机会影响孩子的视力而伤害眼睛, 孩子玩 手机 10 分钟相当于看电视半小时, 一双 “心灵的窗户” 顿时变得 “暗淡 无神”; 伤及颈椎, 每天玩手机超过 4 小时, $81.6 \%$ 的人不同程度的出现 了脊柱侧弯, 笔直的身体成了佝偻半残之躯; 麻木神经, 表现为眼神呆 滞、耳背不灵; 性情冷漠, 性格怪异躁动, 再也见不到曾经的阳光少年。

其次荒废学业断送前程。玩手机会浪费孩子的时间，大好光阴从指 间流逝; 课堂无心学习, 注意力不集中; 胸无斗志, 力不从心, 多少英 才少年名落孙山。

再次祸及生命。玩手机造成孩子有可能出现有离家出走的，有沉迷 于虚拟世界自杀的，有数日 “手游” 虚脱 “坐化” 的，有因没收手机发 生争执跳楼的……触目惊心，惨不忍睹。

\section{2 手机成瘾的原因}

分析手机成瘾的原因, 是为了更好的认识、预防和治疗手机成瘾。 手机成瘾的原因是多方面的, 有社会大环境因素, 有学校教育的因素, 当然更有家庭教育的因素，其中家庭教育是手机成瘾的重要原因与罪魁 祸首, 冰冻三尺非一日之寒。

一是源于父母的 “暗示”。

孩子本身或多或少遗传父母基因,再加上有的家长有空就抱着手机、 电视、电脑不放, 孩子从小好奇心性强，见父母、家长、大人们都抱着 手机, 想走进手机世界探个究竟……原来手机有这般神奇, 从好奇到模 仿, 最后爱上了手机。

\section{二是源于孩子的孤独。}

家长忙工作早出晚归, 做生意起早贪黑, 搞应酬数日不归 $\cdots \cdot . \cdot$, 家 长们不是身心疲急力不从心, 就是抱着手机、守着牌桌、干着自己的娱
乐, 把孩子晾在了一边, 都影响了孩子身心健全发育。孩子需要父母关 注与陪伴, 如果他们感受不到父母的重视, 就会产生孤独感, 就会用别 的东西打发自己, 而手机功能强大, 可以最大限度驱散孩子的孤独感, 于是孩子粘上了手机。

三是源于家长的懒惰与溺爱。

网易总裁丁磊说 “很多家长是因为懒，才会让孩子玩手机来解放自 己”, 有的家长为了打牌不受干扰，抛给孩子一个手机; 面对孩子哭闹不 止, 父母不是想办法去哄哄, 而是抛给他们一个手机……。让当孩子在 不知不觉的爱上了手机, 纵观这些现象的发生, 家长不是因为没有用心 的关注孩子，而是因为懒，或者因为溺爱下不了狠心，没能即时制止， 甚至过早的给孩子购买了手机。家长今天对孩子无原则的溺爱，就是给 自己明天埋下 “麻烦” 的种子。

四是源于孩子受挫得不到家长的关心与帮助。孩子同伴的排斥、老 师的批评、成绩的退步、失恋等等现象, 会让孩子受了委屈无处申诉, 遭了挫折无人帮助, 于是手机成了知心朋友和排忧解难的工具, 孩子在 手机世界里想哭就哭、想闹就闹，丝毫无所顾忌。

五是源于家庭环境的不和谐。父母感情不和经常吵架，整个家庭关 系紧张, 充满着恐惧感, 还有个别家庭离异而缺少健全的父爱或者母爱 等等, 孩子为了寻找温暖、逃避现实、消除恐惧, 不少孩子就这样沉浸 在手机的虚拟世界之中。

\section{3 防治手机成瘾的措施}

3.1 预防为主，防范未然。

3.1.1家长以身作则做出榜样。

父母家长要少玩手机、不玩手机, 实在有瘾或因工作之需, 尽量不 要在孩子面前玩手机，让孩子少看见手机，消除孩子的念想。曾经在高 铁上见到一对母子, 妈妈捧着一本《瓦尔登湖》读着, 儿子坐在旁边饶 有兴趣的翻着《小猪佩奇》书籍, 这是正面榜样, 孩子在母亲的榜样中 耳濡目染。

3.1 .2 创设和谐的家庭环境。

没有喋喋不休, 没有吵闹争斗, 没有家庭暴力, 没有亲情的缺失的 家庭环境，始终会让孩子感受家庭的温暖，家庭的和谐。 


\section{1.3 多陪伴孩子消除孤独。}

孩子孤独就会寻找寄托, 寄托可能会玩上手机等。家长陪伴孩子既 是消除孩子的孤独的需要, 也是对亲情的最好诠释。陪伴分为主动陪伴 和被动陪伴: 主动陪伴是指家长按着自己的目标和意愿积极主动地陪伴 在孩子身边引导他们, 如陪伴他们写几个字、唱几首歌、讲几个故事, 或者带孩子出去游玩认识一些新生鲜事物; 被动陪伴是指陪站在孩子身 边静静的欣赏他们, 顺着他们的娱乐活动扮演他们的伙伴, 接着他们的 话题聊聊天, 做他们的知心朋友, 有时家长也可以把握机会将自己的教 育目标融于被动陪伴之中。

3. 1.4 从小培养孩子广泛的兴趣爱好。

孩子们并不是天生爱玩手机, 他们都有天生的兴趣爱好, 比如音乐、 绘画、舞蹈、体育、阅读等。现在手机成瘾的孩子几乎没有广泛的兴趣 爱好, 家长要把孩子的教育作为一个课题来研究, 在陪伴中发现他们健 康的兴趣爱好并加以培植, 变成他们的特长。兴趣一旦成了他们的特长, 成了他们引以为荣的事, 他们寂寞时就有了寄托。孩子的兴趣爱好不仅 是靠发现, 还可以由父母引导产生。有个小学三年级的孩子, 曾经并不 怎么喜欢乐器, 更不愿去学钢琴, 于是父母想了个办法, 带他去一所乐 器学校, 当他们看到各色各样的乐器时, 父母指着金黄色的萨克斯说“这 是黄金做的”, 孩子听说是黄金做的, 顿时两眼发光、心痒痒的, 父母趁 热打铁 “我们买一个玩玩, 吹吹好吗? ” 孩子答应了, 从此学上了萨克 斯, 接着钢琴、葫芦触类旁通。随着年龄增长, 孩子有时间便玩乐器, 手机自然不会上瘾。

\subsection{5 从小教导进行潜移默化教育。}

孩子来到人世三种情绪: 好奇、害怕、爱。好奇心重, 害怕减少, 害怕情绪减少就会产生爱。因此家长必须从小教导孩子, 让他们认识到 手机上瘾的危害。利用生活中的正反面事例反复说教, 进行潜移默化的 教育。例如张三变坏了、李四成绩下降了、王五进监狱了等等, 都可说 成是手机成瘾造成的后果, 让他们产生害怕心理, 而不敢过多玩弄手机; 也可以把周边一些成功人士尤其是他们喜欢的人和事, 说成是他们认真 读书、很少玩手机、游戏的原因。正反事例越来越多, 时间愈来愈久, 在正反对比中孩子自会产生明智的选择。

3.2 及时纠正, 科学施策。

如果孩子手机已经上瘾, 家长必须及时纠正、科学施策。但具体问 题必须具体分析，不同年龄段的孩子采取不同的防治方法。

\subsection{1 对待儿童时期孩子手机成瘾的对策。}

对待儿童时期的孩子手机成瘾时, 首先家长要统一意见, 无论孩子 哭也好闹也罢, 决不能心慈手软, 必须 “没收手机”。今天我们对孩子的 心慈手软就是明天孩子对手机的纠缠不清; 今天我们对孩子无原则的溺 爱, 就是对自己的明天埋下 “祸根”, 长痛不如短痛, 快刀斩乱麻。其次 家长要讲清道理与危害, 让教育入心入肺。再次转移孩子的注意力, 将 孩子的注意力转移到其他健康的兴趣爱好上, 父母可以带小孩遜遜公园、 爬爬山、看看电影等等。最后家长可以跟孩子约法三章, “玩好” 手机: 一方面手机里有孩子的格局、理想和视野, 一味的禁止只会兹生孩子的
逆反心理, 堵则溃, 疏则通; 另一方面手机等电子产品是孩子认识世界 的望远镜、探索世界的工具, 盲目的禁止无异于 “闭关锁国”, 孩子会被 同学淘汰而陷入孤立。因此手机不是洪水猛兽, 但须约法三章。一是什 么时间玩, 手机、电脑必须掌握在家长手中, 具有可控性; 二是玩多长 时间, 一般来说一天不能超过 60 分钟, 对于幼儿, 家长可以设定时间或 者把握手机电量让手机 60 分钟后自动关机; 三是玩什么内容, 家长可以 提前下载一些益智游戏、有益身心健康的动画片, 让孩子体会其中的乐 趣, 避免恶意软件趁虚而入, 以免孩子蒙受错误诱导。约法三章后孩子 必须遵守, 否则给以处罚, 惩罚孩子第二天不能玩手机等等。通过约法 三章, 既可以培养孩子的自控能力、承担过错的担当精神, 又能让孩子 从手机中的益智教育中开启智力。

3. 2.2 对待青春叛逆期孩子手机成瘾的对策。

对待青春叛逆期的孩子手机成瘾时, 家长不能简单粗暴的没收手机 或者痛打一顿, 否则可能会出现不可收拾的场面, 多少离家出走、自虐 身亡、跳楼现象多半出现在青春叛逆期。在青春叛逆期, 想要戒除孩子 的手机瘾, 必须慎之又慎。在文中述措施之中，笔者更偏向于对孩子讲 清道理、说明危害。但这个年龄段的孩子很自负, 虽然知道其中的危害, 但还是不会放在心上, 或者说手机成瘾已病入膏育。此时戒除手机成瘾 必须讲过程, 约法三章必须分步实施, 例如由原来每天玩 3-4 个小时, 改成每天玩 2 个小时, 然后再慢慢改成 1 个小时。孩子在这过程中肯定 是痛苦难謷的, 此时家长必须保持高度警惕, 密切关注孩子异常行为, 用心陪伴孩子，带孩子做他们其他相对喜欢做的事，如全家外出旅游、 做点孩子爱吃的饭菜、买些孩子喜欢的衣服, 但坚决不要谈及学习上的 事, 更不能给他们定学习目标。因为他们现在根本无心学习, 这样做会 让孩子反感甚至恼怒。家长应该根据孩子的志趣与爱好认真把握, 八仙 过海各显神通, 但是转移注意力的活动必须是健康的, 否则就像戒烟的 人, 戒了烟又啃上了槟楖, 从一个泥坑跳进了另一个泥坑。此外在纠正 手机上瘾的过程中, 有时还需借助外力, 让孩子相好的朋友一道陪伴、 开展健康的活动, 但对异性朋友要多个心眼, 防止另一个泥坑 “早恋”。

总之, 没有任何一项事业比创造优秀的孩子更伟大, 孩子的教育等 不得, 家长的任何成功都无法弥补在孩子教育上的失败, 孩子的教育误 不起, 我们必须全面认识手机瘾毒, 及早预防, 及时防治。

\section{[基金项目]}

本文系湖南省 “十三五”规划 2020 年度课题《“互联网+”背景 下农村中小学家长学校建设研究与实践》( 课题编号: XJK20CJC077）的阶段性成果。

\section{[参考文献]}

[1]邱琦.互联网十时代家校共育新模式探索[J].才智,2019,13(34):223.

[2]击兴星.论互联网在家校共育中的有效应用[J]. 学周 刊,2019,26(33):184.

[3]王玉."互联网+"时代高职院校家校互动新模式的探寻[J].河北农 机,2019,10(11):126. 